\title{
A CONDIÇÃO DO TRABALHADOR IDOSO APOSENTADO DIANTE DA (IR)RETRIBUTIVIDADE DA PREVIDÊNCIA SOCIAL E O IMPACTO AOS DIREITOS DA PERSONALIDADE
}

\author{
Leda Maria Messias da Silva* \\ Leticia Mayumi Almeida Takeshita**
}

RESUMO: Analisa-se a condição do idoso que, com aposentadoria em valor ínfimo, continua laborando e recolhendo para a Previdência, sem contrapartida. Via método dedutivo, descrevem-se os motivos para a (re)inserção do idoso no mercado de trabalho. Aborda-se a situação em que o idoso adoece ou sofre acidente de trabalho e não tem direito, com contrato suspenso, ao correspondente benefício, apesar de recolher contribuições previdenciárias. Diante dessa inconstitucionalidade, examinam-se os direitos da personalidade, notadamente a vida, concluindo-se pela (in)dignidade do trabalhador idoso, que aufere, geralmente, montante ínfimo em aposentadoria, contribuir à Previdência, sem contrapartida, e tendo lesados seus direitos da personalidade.

Palavras-chave: Trabalhador idoso aposentado. Insuficiência da aposentadoria. (Ir)retributividade da Previdência Social. Direitos da personalidade. Saúde.

\section{THE CONDITION OF THE RETIRED ELDERLY WORKER FACED WITH THE (IR)RETRIBUTIVITY OF SOCIAL WELFARE AND ITS IMPACT ON PERSONALITY RIGHTS}

\begin{abstract}
It analyses the condition of the elderly that, with minimal retirement, continues working and collecting to Welfare, without compensation. Through deductive method, it describes the reasons for the (re)insertion of the elderly in the job market. It adresses the situation that the elderly becomes ill or suffers an accident at work and is not entitled, with suspended contract, to the benefit, despite contributing. Due to this unconstitutionality, it examines personality rights, specially life, concluding by (in)dignity of the elderly worker, that often earns a small amount in retirement, contributing to Welfare, without compensation, and having injured their personality rights.
\end{abstract}

\footnotetext{
* Pós-doutora em DIREITO, pela Universidade de Lisboa-Portugal (2012); doutora em Direito pela Pontifícia Universidade Católica de São Paulo (2004); mestrado em Direito pela Pontifícia Universidade Católica de São Paulo (1995); Professora do doutorado, mestrado e graduação da Universidade Cesumar - UNICESUMAR e da graduação e pós-graduação da Universidade Estadual de Maringá-PR; ex-professora da Universidade Cândido Mendes, no Rio de Janeiro-RJ; pesquisadora em Grupo de Pesquisa, junto ao CNPQ e do Instituto Cesumar de Ciência, Tecnologia e Inovação, bolsista de produtividade em pesquisa do ICETI, advogada. Maringá-PR. Email: leda.silva@unicesumar.edu.br.

** Mestranda em Ciências Jurídicas, pela Universidade Cesumar - UNICESUMAR; pós-graduanda em Direito Processual Civil, pela Faculdade Maringá; integrante de grupo de pesquisa junto ao CNPQ; graduação em Direito, pela Universidade Estadual de Maringá. Maringá-PR. E-mail: leticiatake@ hotmail.com.
} 
Keywords: Retired elderly worker. Insufficiency of retirement. (Ir)retributivity of Social Welfare. Personality rights. Health.

\section{INTRODUÇÃO}

É de sabença cursiva que nas últimas décadas verificou-se o advento do aumento da longevidade, propiciado pelo desenvolvimento da ciência, especialmente da medicina, aliado à inserção da mulher no mercado de trabalho e a consequente redução da taxa de fecundidade.

Desse modo, inúmeros desafios desvelaram-se à sociedade, a exemplo do surgimento de novos arranjos familiares, destacando-se, inclusive, aqueles em que o idoso é arrimo de família, ou seja, em que a renda do idoso, deve suportar além de seu próprio sustento, muitas vezes, o de sua família.

Entretanto, no que concerne à renda proveniente dos proventos da aposentadoria, verifica-se, que não raro, é deveras insuficiente até mesmo para o ancião manter sua subsistência, incluindo as despesas básicas com saúde.

Assim sendo, encontra como solução sua (re)inserção no mercado de trabalho, deparando-se com o dever de continuar contribuindo para a previdência, não obstante sejam assaz escassas as contrapartidas, podendo-se aludir mesmo à irretributividade do sistema.

Ademais, ao trabalhador idoso aposentado também é vedado, quando da suspensão de seu contrato de trabalho em decorrência de doença ou acidente de trabalho, o recebimento do benefício equivalente, de modo que o ancião resta desprotegido.

Para tanto, o presente trabalho inicia-se com a descrição do conceito de ser idoso no Brasil, notadamente no plano jurídico, relacionando-se com sua reinserção no mercado de trabalho após a aposentadoria, em decorrência da insuficiência de renda para arcar com despesas básicas, como medicamentos.

Subsequentemente, disserta-se acerca das principais características da Previdência Social, em especial de constituir sistema contributivo e retributivo, aspectos que repercutem na condição indigna que se encontra o trabalhador idoso aposentado, vez que apesar de ter de continuar recolhendo para a previdência, não é acobertado por muitos de seus benefícios.

Procede-se, então, ao exame dos direitos de personalidade, haja vista que são deveras ofendidos, especialmente o direito à vida, quando o trabalhador idoso aposentado adoece ou sofre acidente de trabalho, e lhe é vedado o correspondente benefício previdenciário. 
Nessa senda, analisa-se sobretudo a jurisprudência no que concerne à hodierna impossibilidade de o trabalhador aposentado receber contrapartida oriunda do desconto em seu salário referente às contribuições sociais, que é obrigado a efetuar.

No que tange à metodologia, servir-se-á do método dedutivo, possuindo como ponto de partida as ocorrências no meio ambiente da pessoa idosa. Ademais, utilizar-se-á como instrumento de pesquisa, bibliografias, artigos e demais doutrinas, bem como da técnica da documentação indireta, mediante pesquisa jurisprudencial e legal.

\section{O IDOSO APOSENTADO QUE PERMANECE OU RETORNA AO MERCADO DE TRABALHO}

De início, cabe apontar que o conceito jurídico de idoso restou estabelecido pela Lei n $10.741 / 2003$, também conhecida como Estatuto do Idoso, que em seu art. $1^{\text {o }}$ consta ser a pessoa com sessenta ou mais anos de idade. Aliás, com fulcro no mesmo diploma, dispõe-se ser o envelhecimento um direito personalíssimo, e sua proteção um direito social, conforme art. $8^{\circ}$ (BRASIL, 2003).

À temática é conferido maior realce, sobretudo com o aumento da expectativa de vida, resultado do avanço nos estudos da ciência, mormente da medicina, inserção da mulher no mercado de trabalho, e consequente redução da taxa de fecundidade.

Acresça-se, ainda, a alteração nos arranjos familiares, passando-se de famílias numerosas a famílias com número cada vez menor de membros. Nesse sentido, destaca-se a frequente composição familiar em que o idoso é arrimo de família, ocupando, portanto, papel central no sustento de seus familiares.

Razão outra para a corresidência dos idosos com os demais membros de sua família deflui da redução do apoio por parte do Estado à pessoa de idade longeva. Sob esse prisma, afirmam Ana Amélia Camarano, Solange Kanso e Juliana Leitão e Mello (2004, p. 52-53):

\footnotetext{
A hipótese do trabalho é que dada a predominância em quase todo o mundo, de um modelo de políticas sociais que privilegia o enxugamento do Estado, as famílias estão sendo cada vez mais requeridas para cuidar dos segmentos "vulneráveis". Em muitos países, aparece como a única alternativa de apoio à população idosa. Isso tem se dado tanto pela co-residência como pela transferência de bens e recursos financeiros. Os seus membros se ajudam na busca do bem-estar coletivo, constituindo um espaço de "conflito cooperativo" em que se cruzam as diferenças entre homens e mulheres e as intergeracionais. Daí surge uma gama variada de arranjos familiares.
} 
Há de se mencionar, ainda, que se verifica hodiernamente que a renda do idoso, em que, na maioria das vezes, inclui-se a aposentadoria, não tem se demonstrado suficiente para suportar as despesas, inclusive, ordinárias.

Nesse sentido, Claudia Lima Marques e Bruno Miragem retratam que o ancião, em face dos diminutos valores provenientes da aposentadoria, por vezes, vale-se do recurso aos empréstimos financeiros, o que expõe ainda mais sua vulnerabilidade (2014, p. 149-150):

Por fim, cumpre lembrar em relação ao consumidor idoso, as recentes contratações
de empréstimos financeiros com pagamento consignado em folha, permitidos pela
autarquia responsável pelos benefícios e proventos de aposentadorias da Previdência
Social. Trata-se, também nestes casos, de uma contratação em que deve se ter em
conta a vulnerabilidade agravada do idoso, em especial em face da realidade social
dos baixos valores pagos pela Previdência Social, que fazem do recurso ao
empréstimo consignado em folha de pagamento, muitas vezes, uma necessidade do
consumidor idoso para atendimento de despesas ordinárias pessoais ou ainda, em
vista da taxa de juros favorecida, como recurso para o atendimento das necessidades
de parentes ou amigos próximos.

Acresça-se, igualmente, a constante desvalorização, por parte da sociedade, às pessoas de idade mais avançada. É o que registram Leda Maria Messias da Silva e Jalane Tansin Kloster (2009, p. 608):

Apesar da abordagem do assunto em diversas doutrinas, a sua real importância ainda
não foi valorizada na prática, uma vez que os homens são os responsáveis pela
discriminação e marginalização da pessoa mais velha, os envelhecentes, ou seja, a
pessoa apta ao trabalho após os quarenta anos. Talvez, por não parar para pensar que
estão preparando o próprio fado, mais cedo ou mais tarde.

As características da discriminação e marginalização são igualmente percebidas quando a pessoa idosa, diante da premente necessidade de manter sua subsistência, e por vezes, de sua família, face ao ínfimo valor recebido a título de aposentadoria, permanece ou regressa ao mercado de trabalho.

Com referido (re)ingresso, inobstante já ser aposentado, o idoso é obrigado a continuar a ter descontado mensalmente de seu salário a importância relativa à contribuição previdenciária, sendo que praticamente inexistentes os benefícios que, eventualmente, pode adquirir, em contrapartida.

Com efeito, para maior compreensão, extrai-se a relevância da exploração do tema, levando-se em consideração o sistema da previdência social, de caráter contributivo, realizando-se cotejo com a figura do idoso aposentado, que aliás, é frequentemente visualizado pelo senso comum como um fardo, isto é, um peso às contas públicas. Eis o assunto do capítulo adiante. 


\section{A (IR)RETRIBUTIVIDADE DA PREVIDÊNCIA SOCIAL AO TRABALHADOR APOSENTADO}

Inicialmente, faz-se necessário apontar que a previdência social consiste em vertente da seguridade social, em consonância com o caput do art. 194 da Constituição Federal ${ }^{1}$. Possui por características o caráter contributivo e a filiação obrigatória, visando à preservação do equilíbrio financeiro e atuarial, nos termos do caput do art. 201 do mesmo diploma normativo ${ }^{2}$ (BRASIL, 1988).

Quanto à contributividade, reside no fato em que para usufruir dos benefícios previdenciários constitui requisito verter mensalmente as correspondentes contribuições. Aludidas contrapartidas referem-se aos meios de o beneficiário se manter, conforme está consubstanciado no caput do art. $3^{\circ}$ da Lei no $8.212 / 1991^{3}$ (BRASIL, 1991a).

Insta salientar, especificamente, que o aposentado que permanecer laborando ou que retornar ao mercado de trabalho é considerado segurado obrigatório do Regime Geral de Previdência Social - RGPS, e, por conseguinte, deve efetuar as contribuições previdenciárias, a fim de auxiliar no custeio da Seguridade Social, nos moldes do art. 12, §4 ${ }^{\circ}$ da Lei ${ }^{\circ}$ 8.212/1991 (BRASIL, 1991a).

Portanto, prima facie, poderia se entender que da contribuição efetuada pelo trabalhador aposentado decorreria a efetiva possibilidade de auferir contraprestação, como de regra ocorre. Eis o que preconizam Eduardo Rocha Dias e José Leandro Monteiro de Macêdo (2012, p. 43): “A proteção previdenciária exige a contribuição direta do protegido no custeio de suas ações como condição necessária para a qualificação do direito subjetivo à proteção previdenciária".

\footnotetext{
${ }^{1}$ CF/88 - Art. 194. A seguridade social compreende um conjunto integrado de ações de iniciativa dos Poderes Públicos e da sociedade, destinadas a assegurar os direitos relativos à saúde, à previdência e à assistência social [...] (BRASIL, 1988).

${ }^{2}$ Art. 201. A previdência social será organizada sob a forma do Regime Geral de Previdência Social, de caráter contributivo e de filiação obrigatória, observados critérios que preservem o equilíbrio financeiro e atuarial, e atenderá, na forma da lei, a: (Redação dada pela Emenda Constitucional n ${ }^{103}$, de 2019) [...] (BRASIL, 1988).

${ }^{3}$ Art. $3^{\circ}$ A Previdência Social tem por fim assegurar aos seus beneficiários meios indispensáveis de manutenção, por motivo de incapacidade, idade avançada, tempo de serviço, desemprego involuntário, encargos de família e reclusão ou morte daqueles de quem dependiam economicamente [...] (BRASIL, 1991).

${ }^{4}$ Art. 12. São segurados obrigatórios da Previdência Social as seguintes pessoas físicas: [...] $\S 4^{\circ} \mathrm{O}$ aposentado pelo Regime Geral de Previdência Social-RGPS que estiver exercendo ou que voltar a exercer atividade abrangida por este Regime é segurado obrigatório em relação a essa atividade, ficando sujeito às contribuições de que trata esta Lei, para fins de custeio da Seguridade Social [...] (Incluído pela Lei ${ }^{\circ}$ 9.032, de 28.4.95) (BRASIL, 1991).
} 
Contudo, a efetiva contraprestação é vedada por força do art. $18, \S 2^{\circ}$ da Lei $n^{\circ}$ $8.213 / 1991^{5}$, em conformidade com o qual apenas estão disponíveis ao trabalhador aposentado, quando este eventualmente prescinda, o salário-família e a reabilitação profissional (BRASIL, 1991b). Nessa linha, não é preciso envidar muito esforço para se concluir que praticamente de completa inviabilidade os retromencionados benefícios, tendo em vista a própria condição do avanço da idade.

Outro ponto digno de relevo concerne ao princípio da isonomia, consubstanciado no caput do art. $5^{\circ}$ da Constituição Federal, segundo o qual “[...] todos são iguais perante a lei, sem distinção de qualquer natureza [...]” (BRASIL, 1988). É que restaria inviabilizada a consecução do referido princípio, vez que, diferentemente dos demais trabalhadores, aqueles já aposentados não aufeririam qualquer benefício efetivo da Previdência Social, não obstante contribuírem para tal. Nesse sentido, sustentam Antonio Lopes Monteiro e Roberto Fleury de Souza Bertagni (2020, p. 90):

Mais ainda, tal dispositivo fere o princípio constitucional da isonomia. Por que tratar
desigualmente os trabalhadores que estão na ativa, aposentados e não aposentados?
O que deve ser respeitado é a igualdade de direitos de todos os
segurados-empregados quanto aos riscos e ao seguro de acidente do trabalho
(independentemente de ser aposentado ou não, porque a situação jurídica, perante a
Previdência, é de segurado-empregado).

Dessa forma, vislumbra-se a situação de injustiça em que enquanto um trabalhador não aposentado recebe benefício previdenciário quando da suspensão de seu contrato de trabalho proveniente de acidente de trabalho (in casu) ou doença, o mesmo não ocorre com um trabalhador aposentado, e não raro, idoso.

Logo, é questionável o dever de o idoso ter de contribuir para a previdência, diante das variadas desvantagens. Todavia, essa conjuntura é sustentada e, pode-se dizer, chancelada pelo Supremo Tribunal Federal (STF), que elenca como lastro o princípio da solidariedade. A título de exemplo, é o Agravo Regimental em Recurso Extraordinário n 430.418, no bojo do qual se apresenta o entendimento desta Corte:

\begin{tabular}{llllll} 
AGRAVO & \multicolumn{2}{c}{ REGIMENTAL } & \multicolumn{2}{c}{ EM } & \multicolumn{2}{c}{ RECURSO } & \multicolumn{2}{c}{ EXTRAORDINÁRIO. } \\
CONTRIBUIÇÃO & SOCIAL & DO & APOSENTADO & QUE & RETORNA À \\
ATIVIDADE. & POSSIBILIDADE. & PRINCÍPIO & DA & SOLIDARIEDADE.
\end{tabular}

\footnotetext{
${ }^{5}$ Art. 18. O Regime Geral de Previdência Social compreende as seguintes prestações, devidas inclusive em razão de eventos decorrentes de acidente do trabalho, expressas em benefícios e serviços: [...] $2^{\circ} \mathrm{O}$ aposentado pelo Regime Geral de Previdência Social-RGPS que permanecer em atividade sujeita a este Regime, ou a ele retornar, não fará jus a prestação alguma da Previdência Social em decorrência do exercício dessa atividade, exceto ao salário-família e à reabilitação profissional, quando empregado. (Redação dada pela Lei $n^{\circ} 9.528$, de 1997) (BRASIL, 1991).
} 
PRECEDENTES. O Supremo Tribunal Federal consolidou o entendimento de que é constitucional a cobrança de contribuição previdenciária sobre o salário do aposentado que retorna à atividade. $\mathrm{O}$ princípio da solidariedade faz com que a referibilidade das contribuições sociais alcance a maior amplitude possível, de modo que não há uma correlação necessária e indispensável entre o dever de contribuir e a possibilidade de auferir proveito das contribuições vertidas em favor da seguridade. Agravo regimental a que se nega provimento (BRASIL, 2014).

Nesse prisma, faz-se alusão à Repercussão Geral no Recurso Extraordinário com Agravo 1.224.327-ES, no âmbito do Supremo Tribunal Federal, ao qual se conferiu repercussão geral e julgou-se o mérito de modo a endossar a jurisprudência da Corte no sentido da possibilidade da cobrança da contribuição previdenciária, com lastro no princípio da solidariedade (BRASIL, 2019).

Ora, acresça-se que apesar de se reconhecer a complexidade em se equilibrar as contas públicas, o princípio citado, qual seja, o da solidariedade, é utilizado em detrimento da própria dignidade da pessoa humana, princípio fundante do diploma constitucional.

Nas palavras de Paula Gabriele Bandeira Rodrigues e Elirani de Sousa Chinaglia (2019, p. 155) “observa-se que nesse caso o sistema previdenciário deixa prevalecer o princípio da solidariedade em detrimento do da dignidade humana, o que não se mostra correto, uma vez que a dignidade humana é a razão de existência da própria previdência”. E como ficaria a solidariedade em relação àquele que doente ou acidentado e sem parte do seu rendimento, passa necessidade?

Nesse sentido, juristas há que defendem a aplicação do princípio da solidariedade ao trabalhador idoso aposentado. Exemplificativamente, são as palavras de João Ernesto Aragonés Vianna (2014, p. 213-214):

A um, pelos argumentos acima expostos, fundados na solidariedade contributiva; a
dois, porque o artigo $18, \S 2 \mathrm{o}$, da Lei no $8.213 / 91$ arrola os benefícios que são
devidos ao segurado aposentado; [...] e finalmente, a três, porque segundo o artigo
$201, \S 11$, da $\mathrm{CF} / 88$, "os ganhos habituais do empregado, a qualquer título, serão
incorporados ao salário para efeito de contribuição previdenciária e consequente
repercussão em benefícios, nos casos e na forma da lei", ou seja, a Constituição
Federal deixa claro que cabe à lei ordinária determinar os casos em que as
contribuições terão - ou não - repercussão em benefícios, nada impedindo a
existência de casos onde as contribuiçôes não repercutirão em benefícios. Isso é
assim devido à solidariedade.

Entretanto, já se mencionou aqui a inviabilidade dos benefícios concedidos ao trabalhador idoso aposentado. Resta, desse modo, a ofensa a diversos princípios, corporificados, por exemplo, na isonomia e na dignidade da pessoa humana. 
É de se mencionar, ainda, a intensa celeuma engendrada acerca da possibilidade ou não da desaposentação e da reaposentação, discussão que alcançou o Supremo Tribunal Federal. O primeiro instituto refere-se à hipótese de renúncia à aposentadoria, a fim de solicitar revisão do benefício. Já a reaposentação compreende novo cálculo previdenciário, levando-se em consideração as contribuições efetuadas no novo período, ou seja, após a primeira aposentadoria.

Quanto à desaposentação, já havia sido vedada em 2016, estabelecendo-se o Tema 503 do STF (Recurso Extraordinário 661256), referente à conversão de aposentadoria proporcional em aposentadoria integral por meio do instituto da desaposentação (BRASIL, 2020b).

Por seu turno, em 2020, entendeu-se igualmente pela impossibilidade da reaposentação, razão pela qual o referido tema ganhou acréscimo nesse sentido, constando-se a decisão da seguinte maneira: No âmbito do Regime Geral de Previdência Social - RGPS, “somente lei pode criar benefícios e vantagens previdenciárias, não havendo, por ora, previsão legal do direito à 'desaposentação' ou à 'reaposentação', sendo constitucional a regra do art. 18, §2º da Lei no 8.213/91" (BRASIL, 2020b).

Com efeito, revela-se indene de dúvidas que o idoso aposentado que continua laborando, e, portanto, contribuindo para a Previdência Social, não recebe qualquer contrapartida, sendo-lhe vedado, inclusive, a possibilidade de optar por aposentadoria mais benéfica, mediante a desaposentação ou reaposentação.

Nesse diapasão, é possível afirmar o enriquecimento ilícito por parte do Estado, pois recebe a contribuição oriunda da previdência e não fornece contrapartida, com exceção do salário-família e da reabilitação profissional, que como já foi aludido anteriormente, em face das suas condições de idoso dificilmente gozaria.

Emerson Gabardo e Thiago Priess Valiati (2015, p. 258) efetuam relevantes considerações que se enquadram na temática da necessidade de contribuição previdenciária, não obstante relacionada aos servidores inativos:

Em verdade, cobrar após a aposentação significa impor um verdadeiro imposto sobre os proventos dos servidores inativos - uma redução salarial travestida de "contribuição". Mais do que isso: significa, na realidade, a configuração de confisco, vedado expressamente pela Constituição Federal.

Frisa-se que se presume erroneamente que o idoso aposentado já estaria suficientemente guarnecido pelo valor conferido a título de aposentadoria. No entanto, não é o 
que se demonstra na realidade, eis que grande parte permanece ou retorna ao trabalho, notadamente em razão da insuficiência de renda, que compromete as despesas ordinárias, inclusive com a saúde, principalmente em se tratando de idoso.

Nessa perspectiva, alude-se ao Projeto de Lei no 4851/2020, apresentado à Câmara dos Deputados na recente data de 7 de outubro de 2020, de autoria do Deputado Capitão Alberto Neto. Tem por condão retirar a condição de segurado obrigatório ao aposentado que permanece ou retorna ao trabalho, de modo a não incidir sobre sua remuneração as contribuições previdenciárias (BRASIL, 2020a).

Portanto, resta incontroverso o cenário de desvantagem que se apresenta para o aposentado, que por conseguinte, frequentemente opta por inserir-se no mercado de trabalho informal, em que não terá de ter descontado de seu salário o montante equivalente às contribuições previdenciárias realizadas.

Destarte, evidente que a insuficiência da renda da aposentadoria é condição que impacta negativamente a saúde do idoso, que se vê compelido a retornar ao mercado de trabalho para arcar, inclusive, com despesas básicas, como medicamentos. Traz efeitos, portanto, ao mínimo existencial necessário à sobrevivência do trabalhador aposentado. Sobre referido mínimo, aduz Luís Roberto Barroso (2014, p. 85):

\begin{abstract}
Para serem livres, iguais e capazes de exercer uma cidadania responsável, os indivíduos precisam estar além de limiares mínimos de bem-estar, sob pena de a autonomia se tornar uma mera ficção, e a verdadeira dignidade humana não existir. Isso exige o acesso a algumas prestações essenciais - como educação básica e serviços de saúde - , assim como a satisfação de algumas necessidades elementares, como alimentação, água, vestuário e abrigo. O mínimo existencial, portanto, está no núcleo essencial dos direitos sociais e econômicos, cuja existência como direitos realmente fundamentais - e não como meros privilégios dependentes do processo político - é bastante controvertida em alguns países.
\end{abstract}

Nessa linha, frisa-se o direito à saúde, não se podendo olvidar que o seu conceito abrange não somente a ausência de doenças, mas o bem-estar em termos gerais, consoante consta da Constituição da Organização Mundial da Saúde: “A saúde é um estado de completo bem-estar físico, mental e social, e não apenas na ausência de doença ou de enfermidade" (OMS, 1946).

Mister apontar, ainda, que o prejuízo alcança inclusive o Estado, que perde em arrecadação em resultado do desestímulo ao trabalho formal, haja vista que as pessoas migram para o mercado de trabalho informal. 


\section{CONDIÇÃO (IN)DIGNA DO TRABALHADOR IDOSO APOSENTADO E O IMPACTO AOS DIREITOS DA PERSONALIDADE}

De início, faz-se necessário delinear o conceito de direitos da personalidade. Tratamse, pois, de direitos inerentes à pessoa enquanto ser humano, tendo por condão a consecução da dignidade da pessoa humana, alçada a princípio fundamental da República Federativa do Brasil, em consonância com o art. $1^{\circ}$, inc. III, do texto constitucional (BRASIL, 1988).

Igualmente, possuem respaldo de ordem infraconstitucional, vez que a temática ocupa lugar de destaque na Lei ${ }^{\circ}$ 10.406/2002 (Código Civil), possuindo capítulo próprio, isto é, o "Capítulo II: Dos Direitos da Personalidade” (BRASIL, 2002).

Desse texto normativo, impende ressaltar não somente a parte final do art. 11, consoante a qual o exercício dos direitos em comento não pode sofrer limitação voluntária ${ }^{6}$, como também o caput do art. 12 que disciplina a possibilidade de exigência de cessão da ameaça ou lesão a direito da personalidade, além da de reclamar perdas e danos, não se excluindo sanções diversas previstas em lei ${ }^{7}$ (BRASIL, 2002).

Além disso, efetua-se alusão à Consolidação das Leis do Trabalho, especificamente ao art. $223-\mathrm{C}^{8}$, em que consta rol, que se entende não ser taxativo, dos direitos da personalidade, dentre os quais se destaca o direito à saúde (BRASIL, 2017).

Cumpre pontuar, em conformidade com Fernanda Borghetti Cantali (2009, p. 136), que os direitos da personalidade possuem teor absoluto, no que diz respeito a serem oponíveis erga omnes:

Portanto, a natureza de direitos absolutos que recai sobre os direitos de personalidade impõe dever jurídico negativo e positivo, cujo intuito é tutelar os bens protegidos por estes direitos. Nesta perspectiva de dever positivo, de auxílio, verifica-se, por exemplo, a relação entre o Estado e o particular. Aquele, além de não poder lesar os direitos da personalidade, respeitando-os, tem o dever de proporcionar condições efetivas para o pleno desenvolvimento existencial da pessoa humana.

\footnotetext{
${ }^{6} \mathrm{CC} / 02$ - Art. 11. Com exceção dos casos previstos em lei, os direitos da personalidade são intransmissíveis e irrenunciáveis, não podendo o seu exercício sofrer limitação voluntária (BRASIL, 2002).

${ }^{7}$ CC/02 - Art. 12. Pode-se exigir que cesse a ameaça, ou a lesão, a direito da personalidade, e reclamar perdas e danos, sem prejuízo de outras sanções previstas em lei [...] (BRASIL, 2002).

${ }^{8}$ CLT - Art. 223-C. A honra, a imagem, a intimidade, a liberdade de ação, a autoestima, a sexualidade, a saúde, o lazer e a integridade física são os bens juridicamente tutelados inerentes à pessoa física. (Incluído pela Lei $\mathrm{n}^{\circ}$ 13.467, de 2017) (BRASIL, 2017).
} 
Portanto, possuem as dimensões negativa e positiva, que possibilitam sua proteção tanto como abstenção quanto como prestação. Nessa senda, cumpre trazer à baila o conceito de direitos da personalidade para Carlos Alberto Bittar (2015, p. 29):

Consideram-se da personalidade os direitos reconhecidos à pessoa humana tomada em si mesma e em suas projeções na sociedade, previstos no ordenamento jurídico exatamente para a defesa de valores inatos no homem, como a vida, a higidez física, a intimidade, o segredo, o respeito, a honra, a intelectualidade e outros tantos.

Outrossim, Adriano de Cupis (2008, p. 24) associa os direitos da personalidade não somente à essência, como também a pressuposto para outros direitos subjetivos:

Por outras palavras, existem certos direitos sem os quais a personalidade restaria uma susceptibilidade completamente irrealizada, privada de todo o valor concreto: direitos sem os quais todos os outros direitos subjetivos perderiam todo o interesse para o indivíduo - o que equivale a dizer que, se eles não existissem, a pessoa não existiria como tal. São esses os chamados "direitos essenciais", com os quais se identificam precisamente os direitos da personalidade.

Particularmente, em razão de sua importância, pode-se sublinhar o direito à vida. Tal direito vincula-se, pois, aos direitos da personalidade, conforme consigna Elimar Szaniawski (2005, p. 157) “o direito à vida não existe por si só, como direito especial de personalidade. O direito à vida vincula-se intimamente a outras tipificações de direitos de personalidade que o complementam, entre os quais o direito à qualidade de vida".

Além disso, o direito à vida na condição de direito da personalidade pode ser relacionado ao envelhecimento, como o faz Roberto Mendes de Freitas Junior (2015, p. 47):

Conclui-se, dessa forma, que não se trata apenas da vida biológica e espiritual, mas da vida social, usufruída de acordo com o princípio da dignidade da pessoa humana. O processo biológico de envelhecimento deve observar a dignidade do idoso, cabendo à sociedade e ao Poder Público evitarem qualquer violação nesse sentido.

Para que seja observado o envelhecimento do indivíduo em condições de dignidade, mister que se cumpra o mínimo existencial. É notadamente esse aspecto que resta inviabilizado quando não somente da insuficiência dos valores de aposentadoria, mas também da inexistência efetiva de contrapartida. Acerca do mínimo existencial, aduz Fabiana Okchstein Kelbert (2011, p. 105-106):

Assim, embora não exista consenso doutrinário quanto à possibilidade de se restringir o mínimo existencial em face dos limites impostos pela reserva do possível, pode-se defender que esta não poderá ser alegada quando em causa a necessidade de preservar a vida e a dignidade da pessoa. Isso também pode ser defendido com apoio na dupla dimensão atribuída ao mínimo existencial: a necessidade de preservar o conteúdo mínimo em prestações indispensáveis para a garantia de uma vida digna, bem como o dever de fornecer essas prestações. 
Com o fito de se atingir a uma vida digna, impende apontar as considerações tecidas por Elimar Szaniawski (2005, p. 158) a respeito da amplitude do direito à qualidade de vida, que, por sua vez, é componente do mínimo existencial:

Por estas razões, o direito à qualidade de vida é construído sobre o princípio da dignidade da pessoa humana, sendo abarcado também pelo direito à autodeterminação do indivíduo, pelo direito à identidade pessoal; pelo direito à saúde, pelo direito de constituir uma família e pelo direito de acesso a um patrimônio mínimo (SZANIAWSKI, 2005, p. 158, grifos do autor).

Logo, é passível de se inferir que ao trabalhador idoso aposentado deve ser garantido o direito à qualidade de vida, fundamentado no princípio da dignidade humana, o que não se observa, todavia, na condição em que atualmente se situa. Igualmente, deve ser assegurado o direito de acesso a um patrimônio mínimo, que consiste, inclusive, em pressuposto para a perfectibilização do direito à saúde.

Salienta-se que não se está aqui a meramente tecer críticas ao valor, muitas vezes, irrisório da aposentadoria, que acaba por estimular a permanência ou retorno ao trabalho do idoso, mas sim asseverar a situação assaz injusta em que além de ter de continuar a contribuir para a previdência não receber contrapartida, exemplificativamente quando da suspensão do contrato de trabalho, decorrente de doença ou acidente de trabalho.

Aliás, Daniel Machado da Rocha (2020, p. 14) repisa ser a previdência social espécie do gênero seguridade social, que abarca, ainda, o plano da saúde e da assistência social:

Como ramo contributivo da seguridade social, a previdência necessita priorizar as
situações de necessidade social consideradas mais graves, situação que está em
consonância com os objetivos fundamentais da Carta Magna de erradicar a pobreza
e reduzir as desigualdades sociais (inciso III do art. $3^{\circ}$ da CF/88).

Todavia, o que se verifica na atual conjuntura em que se veda a contrapartida aos trabalhadores aposentados, geralmente idosos, é diametralmente oposto, não se concretizando, dessa maneira, os aludidos objetivos fundamentais constantes da Constituição Federal.

Oliveira et al. (2014, p. 425) traçam considerações no sentido da necessidade de ajuste nos sistemas previdenciários diante das inúmeras variáveis:

A questão fundamental é como ajustar os sistemas previdenciários em meio a transformações no ambiente econômico, político e social e nas variáveis demográficas, em sociedades com sérios problemas de desigualdade de renda, grande contingente de pessoas fora do mercado formal, baixa escolaridade e governos com sérios problemas orçamentários.

Com efeito, constituem efetivamente variáveis a serem levadas em consideração, adequando-se, por óbvio à imperatividade de os direitos da personalidade dos trabalhadores 
aposentados, geralmente idosos, serem respeitados, com o fito de se alcançar a concretização do princípio da dignidade da pessoa humana.

Nesse sentido, salienta-se o entendimento de Wladimir Novaes Martinez (2015, p. 96), acerca da finalidade a que deve visar a previdência:

\begin{abstract}
Uma previdência com critérios normativos equânimes é aquela capaz de satisfazer as obrigações jacentes, estar preparada para os deveres em relação àqueles que estejam nas proximidades do cenário decantador da pretensão e que corresponda às proposições do programado no pertinente aos futuros beneficiários, suficiente para acudir as despesas do dia a dia, e ajustada economicamente para eventuais variações da massa dentro de uma concepção que se aproxime o mais possível da reserva matemática ideal.
\end{abstract}

Destarte, depreende-se que a previdência, nos moldes atuais, não se desvela, em considerável parte das vezes, como suficiente, até mesmo para despesas ditas como ordinárias, que o trabalhador idoso aposentado tem de suportar, tais como com medicamentos e plano de saúde, de modo a impactar negativamente nos direitos da personalidade à vida e à saúde.

Por fim, ressalta-se que o sistema previdenciário desvela-se efetivamente como irretributivo ao trabalhador idoso aposentado, haja vista que este, apesar da aposentadoria, tem de continuar a verter as contribuições previdenciárias, recebendo, em contrapartida, benefícios, que na prática, não possui condições de usufruir, sobretudo em razão da idade.

\title{
5 CONCLUSÕES
}

Conforme verificou-se, diante da insuficiência do montante da aposentadoria, os idosos, a fim de suportar despesas ordinárias, notadamente com sua saúde, e, portanto, assegurar sua subsistência, enxergam como solução a permanência ou o retorno ao mercado de trabalho.

Nessa (re)inserção, deparam-se com a injusta situação de além de terem de continuar realizando contribuições previdenciárias, ou seja, com o correspondente desconto mensal em seus salários, não auferem contraprestação, com a exceção do salário-família e da reabilitação profissional, benefícios praticamente inviáveis, considerando-se principalmente a faixa etária desse trabalhador.

Além disso, em face de eventual doença ou acidente de trabalho, quando da suspensão do contrato de trabalho, o trabalhador aposentado, não raro, idoso, e, portanto, geralmente mais debilitado física e psicologicamente em razão da idade, resta desamparado 
do equivalente benefício da previdência, impactando negativamente em sua saúde e dignidade.

Outro ponto considerado diz respeito à inviabilidade à desaposentação e à reaposentação, de modo que ao trabalhador idoso aposentado persiste o dever de efetuar a contribuição ao INSS, não sendo-lhe fornecido, a grosso modo, contrapartida.

As razões para tanto concentram-se sobretudo na alusão ao princípio da solidariedade, conforme o qual a coletividade deve contribuir, de modo a sustentar o equilíbrio nas contas públicas e, especialmente no sistema previdenciário.

Olvida-se, no entanto, que o que ocorre na prática é a prevalência de referido princípio em detrimento do princípio da dignidade da pessoa humana, eis que os trabalhadores idosos aposentados são desamparados quando mais precisam, a exemplo da suspensão do contrato de trabalho proveniente de doença ou acidente de trabalho.

São momentos esses em que deve ser endossado que o próprio sistema da previdência é contributivo e retributivo, enquadrando-se na situação do trabalhador aposentado, que respectivamente já laborou e efetuou, portanto, as contribuições, merecendo, logo, a contraprestação ou, no mínimo, não ter este ônus.

Desse modo, são afetados desfavoravelmente os direitos da personalidade do trabalhador em questão, especialmente o direito à vida, que deve ser revestido de qualidade e dignidade, e o direito à saúde. Ademais, deve ser assegurado o direito ao mínimo existencial.

O cenário atual, portanto, é deveras injusto, eis que enquanto prejudicados os trabalhadores idosos aposentados, e inclusive suas famílias, o Estado encontra-se na situação de enriquecimento ilícito, eis que recebe a contribuição previdenciária do idoso, mas não oferece contraprestação.

Enfim, é de suma importância que sejam lançadas luzes à condição indigna em que se encontra o idoso aposentado, que diante da ínfima aposentadoria, mantém-se ou retorna ao mercado de trabalho, deparando-se com o dever de contribuir à previdência e no entanto, sendo desprezados seus direitos da personalidade quando mais necessitam da retributividade do benefício previdenciário.

Nesse diapasão, também como saída, o Congresso Nacional deveria agir, aprovando o Projeto de Lei $\mathrm{n}^{\circ}$ 4851/2020, para extinguir esta cobrança indevida e enriquecimento ilícito do Estado. 


\section{REFERÊNCIAS}

BARROSO, Luís Roberto. A dignidade da pessoa humana no direito constitucional contemporâneo: a construção de um conceito jurídico à luz da jurisprudência mundial. Tradução: Humberto Laport de Mello. 3. reimpr. Belo Horizonte: Fórum, 2014.

BITTAR, Carlos Alberto. Os direitos da personalidade. 8. ed. rev., aum. e mod. por Eduardo C. B. Bittar. São Paulo: Saraiva, 2015.

BRASIL. Câmara dos Deputados. Projeto de Lei $\mathbf{n}^{\mathbf{0}}$ 4851/2020. Altera a Lei $\mathrm{n}^{\mathbf{0}}$ 8.212, de 24 de julho de 1991, para estabelecer que o aposentado pelo Regime Geral de Previdência Social (RGPS) que estiver exercendo ou que voltar a exercer atividade abrangida por aquele regime não é segurado obrigatório em relação a essa atividade, não incidindo sobre sua remuneração as contribuições de que trata esta Lei, para fins de custeio da Seguridade Social; e revoga o § 2o do art. 18 da Lei no 8.213, de 24 de julho de 1991. Brasília, DF: Câmara dos Deputados, [2020a]. Disponível em:

https://www.camara.leg.br/proposicoesWeb/prop_mostrarintegra?codteor=1935246\&filenam e=Tramitacao-PL+4851/2020. Acesso em: 30 nov. 2020.

BRASIL. [Constituição (1988)]. Constituição da República Federativa do Brasil de 1988. Brasília, DF: Presidência da República, [2016]. Disponível em:

http://www.planalto.gov.br/ccivil_03/constituicao/constituicao.htm. Acesso em: 23 nov. 2020.

BRASIL. Decreto $\mathbf{n}^{0}$ 5.452, de $\mathbf{1}^{\mathbf{0}}$ de maio de 1943. Aprova a Consolidação das Leis do Trabalho. Rio de Janeiro, DF: Presidência da República, [1943]. Disponível em: http://www.planalto.gov.br/ccivil_03/decreto-lei/del5452.htm. Acesso em: 25 set. 2020.

BRASIL. Lei $\mathbf{n}^{0}$ 8.212, de 24 de julho de 1991. Dispõe sobre a organização da seguridade social, institui plano de custeio, e dá outras providências. Brasília, DF: Presidência da República, [1991a]. Disponível em: http://www.planalto.gov.br/ccivil_03/leis/18212cons.htm. Acesso em: 2 dez. 2020.

BRASIL. Lei no 8.213, de 24 de julho de 1991. Dispõe sobre os Planos de Benefícios da Previdência Social e dá outras providências. Brasília, DF: Presidência da República, [1991b]. Disponível em: http://www.planalto.gov.br/ccivil_03/leis/18213cons.htm. Acesso em: 24 nov. 2020.

BRASIL. Lei no 10.406, de 10 de janeiro de 2002. Institui o Código Civil. Brasília, DF: Presidência da República, [2002]. Disponível em:

https://presrepublica.jusbrasil.com.br/legislacao/91577/codigo-civil-lei-10406-02. Acesso em: 5 out. 2020.

BRASIL. Lei no 10.741, de $1^{\circ}$ de outubro de 2003. Dispõe sobre o Estatuto do Idoso e dá outras providências sobre a pessoa idosa. Brasília, DF: Presidência da República, [2003]. Disponível em: http://www.planalto.gov.br/ccivil_03/leis/2003/110.741.htm. Acesso em: 24 nov. 2020.

BRASIL. Lei 13.467, de 13 de julho de 2017. Altera a Consolidação das Leis do Trabalho (CLT), aprovada pelo Decreto-Lei $n^{\circ} 5.452$, de $1^{\circ}$ de maio de 1943 , e as Leis $n^{\circ} 6.019$, de 3 
de janeiro de 1974, 8.036, de 11 de maio de 1990, e 8.212, de 24 de julho de 1991, a fim de adequar a legislação às novas relações de trabalho. Brasília, DF: Presidência da República, [2017]. Disponível em: http://www.planalto.gov.br/ccivil_03/_ato2015-

2018/2017/lei/L13467.htm. Acesso em: 5 out. 2020.

BRASIL. Supremo Tribunal Federal. Agravo Regimental em Recurso Especial no 430.418RS. Relator: Min. Roberto Barroso, 6 de maio de 2014. Disponível em: https://stf.jusbrasil.com.br/jurisprudencia/25069320/agreg-no-recurso-extraordinario-re430418-rs-stf/inteiro-teor-118683628. Acesso em: 4 out. 2020.

BRASIL. Supremo Tribunal Federal. Recurso Extraordinário 661256. Repercussão Geral. Tema 503. Conversão de aposentadoria proporcional em aposentadoria integral por meio do instituto da desaposentação. Relator: Roberto Barroso, 2020b. Disponível em: http://www.stf.jus.br/portal/jurisprudenciaRepercussao/verAndamentoProcesso.asp?incidente $=4157562 \&$ numeroProcesso $=661256 \&$ classeProcesso $=R E \&$ numeroTema $=503 \#$. Acesso em: 24 nov. 2020.

BRASIL. Supremo Tribunal Federal. Repercussão Geral no Recurso Extraordinário com Agravo 1.224.327-ES. Relator: Min. Dias Toffoli, 9 de setembro de 2019. Disponível em: http://portal.stf.jus.br/processos/downloadPeca.asp?id=15341607150\&ext=.pdf. Acesso em: 24 nov. 2020.

CAMARANO, Ana Amélia; KANSO, Solange; MELLO, Juliana Leitão e. Como vive o idoso brasileiro? In: CAMARANO, Ana Amélia (org.). Os novos idosos brasileiros: muito além dos 60? Rio de Janeiro: IPEA, 2014. p. 25-73. Disponível em:

https://www.nescon.medicina.ufmg.br/biblioteca/imagem/0191.pdf. Acesso em: 5 out. 2020.

CANTALI, Fernanda Borghetti. Direitos da personalidade: disponibilidade relativa, autonomia privada e dignidade humana. Porto Alegre: Livraria do Advogado, 2009.

CUPIS, Adriano de. Os direitos da personalidade. Tradução: Afonso Celso Furtado Rezende. São Paulo: Quorum, 2008.

DIAS, Eduardo Rocha; MACÊDO, José Leandro Monteiro de. Curso de direito previdenciário. 3. ed. Rio de Janeiro: Forense, 2012.

FREITAS JUNIOR, Roberto Mendes de. Direitos e garantias do idoso: doutrina, jurisprudência e legislação. 3. ed. São Paulo: Atlas, 2015.

GABARDO, Emerson; VALIATI, Thiago Priess. A inconstitucionalidade da instituição de contribuição previdenciária para servidores inativos. Revista de Direito Administrativo, Rio de Janeiro, v. 270, p. 243-282, set./dez. 2015. Disponível em:

http://bibliotecadigital.fgv.br/ojs/index.php/rda/article/view/58743/57536. Acesso em: 5 out. 2020.

KELBERT, Fabiana Okchstein. Reserva do possível e a efetividade dos direitos sociais no direito brasileiro. Porto Alegre: Livraria do Advogado, 2011. 
MARQUES, Claudia Lima; MIRAGEM, Bruno. O novo direito privado e a proteção dos vulneráveis. 2. ed. rev., atual. e ampl. São Paulo: Revista dos Tribunais, 2014.

MARTINEZ, Wladimir Novaes. Princípios de direito previdenciário. 6. ed. São Paulo: LTr, 2015.

MONTEIRO, Antonio Lopes; BERTAGNI, Roberto Fleury de Souza. Acidentes do trabalho e doenças ocupacionais: conceito, processos de conhecimento e de execução e suas questões polêmicas. 10. ed. São Paulo: Saraiva Educação, 2020.

OLIVEIRA, Francisco Eduardo Barreto et al. O Idoso e a Previdência Social. In:

CAMARANO, Ana Amélia (org.). Os novos idosos brasileiros: muito além dos 60 ? Rio de Janeiro: IPEA, 2014. Disponível em:

https://www.ipea.gov.br/portal/index.php?option=com_content\&view=article \&id=5476\&Item $\mathrm{id}=2$. Acesso em: 5 out. 2020.

ORGANIZAÇÃO MUNDIAL DA SAÚDE (OMS). Constituição da Organização Mundial da Saúde (OMS/WHO). 1946. Disponível em:

http://www.direitoshumanos.usp.br/index.php/OMS-Organização-Mundial-da-

Saúde/constituicao-da-organizacao-mundial-da-saude-omswho.html. Acesso em: 1 dez. 2020.

ROCHA, Daniel Machado da. Comentários à lei de benefícios da previdência social. 18. ed. São Paulo: Atlas, 2020.

RODRIGUES, Paula Gabriele Bandeira; CHINAGLIA, Elirani de Sousa. A ausência de contraprestação, pela previdência social ao aposentado contribuinte, ante os princípios previdenciários. Akrópolis, Umuarama, v. 27, n. 2, p. 151-160, jul./dez. 2019. Disponível em: https://revistas.unipar.br/index.php/akropolis/article/view/7678/3867. Acesso em: 5 out. 2020.

SILVA, Leda Maria Messias da; KLOSTER, Jalane Tansin. Idade x dignidade no mercado de trabalho. In: ENCONTRO NACIONAL DO CONPEDI, 18., 2009, Maringá. Anais [...].

Florianópolis: Fundação Boiteux, 2009. p. 600-627. Disponível em:

http://www.publicadireito.com.br/conpedi/anais/36/12_1292.pdf. Acesso em: 30 nov. 2020.

SZANIAWSKI, Elimar. Direitos de personalidade e sua tutela. 2. ed. rev., atual. e ampl. São Paulo: Revista dos Tribunais, 2005.

VIANNA, João Ernesto Aragonés. Curso de direito previdenciário. 7. ed. São Paulo: Atlas, 2014. 